\title{
A Comparison between English and Chinese Commendatory and Derogatory Words: A Study Based on Dictionaries and Thesauri
}

\author{
Keyue Chen \\ College of Chinese Language and Culture, Nankai University, Tianjin, China
}

Keywords: commendatory words, derogatory words, attitudinal words, comparison between English and Chinese, appraisal system

\begin{abstract}
Commendatory and derogatory words are two kinds of words which have additional attitudinal inclination based on the conceptual meaning of the words. Utterers convey their positive or negative attitude towards people, objects, and phenomena in discourses with commendatory and derogatory words both intentionally and unconsciously. This study draws multifaceted comparisons between Chinese and English commendatory and derogatory words from the aspects of scale, distribution of POT (parts of speech), morpheme structure, meaning extension, and application in discourses through statistics and analyses of dictionaries and thesauri.
\end{abstract}

\section{Commendatory and derogatory words}

Commendatory and derogatory meanings are the connotation of positive and negative attitude in addition to the conceptual meaning which only conveys an objective description of the characteristics and qualities of the people, objects, or phenomena the utterers are talking about. One word can have multiple meanings. The commendatory and derogatory words we are discussing in this article are those with at least one attitudinal meanings, including simple commendatory words, simple derogatory words, words with neutral and commendatory meanings, words with neutral and derogatory meanings, and words with neutral, derogatory and commendatory meanings. For example, the word patronize has three definitions on Merriam-Webster (online). Two of the definitions are neutral: to be a frequent or regular customer or client of; to act as patron of: provide aid or support for, and the last one is derogatory: to adopt an air of condescension toward: treat haughtily or coolly.

The attitudinal inclination is, broadly speaking, a type of emotional expression, since normally the commendatory attitude is related to positive emotion and the derogatory negative. Nevertheless, the attitude held by the utterers is pointed to the object being examined, which must be discriminated from the subjective emotion held by the utterers themselves. 


\section{Quantitative analysis of the scale and pot distribution of English and Chinese attitudinal words}

\subsection{The scale of commendatory and derogatory words in both languages}

To make a more objective comparison between English and Chinese commendatory and derogatory words, we counted and analyzed the words in English and Chinese dictionaries and thesauri (Table 1). Currently, the comprehensive dictionary, Modern Chinese Dictionary (7th edition), marks the commendatory and derogatory words with the note “含贬义”(contain derogatory meaning), “多含贬义”(mostly contain derogatory meaning), “多含襄义”(mostly contain commendatory meaning), etc. There are also some Chinese dictionaries especially targeting at attitudinal words, and except for dictionaries, many research teams have released their commendatory and derogatory words thesauri (Both specialized dictionaries and thesauri are listed in Table 1. For more information please see Reference).

Table 1. Quantity comparison between English and Chinese commendatory and derogatory words

\begin{tabular}{|c|c|c|c|}
\hline Dictionaries & Language & Commendatory & Derogatory \\
\hline $\begin{array}{l}\text { Oxford Advanced Learner's Dictionary } \\
\text { (8 } 8^{\text {th }} \text { edition) }\end{array}$ & English & 136 & 1256 \\
\hline Modern Chinese Dictionary ( $7^{\text {th }}$ edition) & Chinese & 2 & 190 \\
\hline $\begin{array}{l}\text { Common Commendatory and } \\
\text { Derogatory Words and Meaning }\end{array}$ & Chinese & 502 & 505 \\
\hline $\begin{array}{r}\text { The Usage of Commendatory and } \\
\text { Derogatory Words in Chinese * }\end{array}$ & Chinese & 486 & 552 \\
\hline Thesauri & Language & Commendatory & Derogatory \\
\hline $\begin{array}{l}\text { HowNet Emotion Words Package of } \\
\text { English }\end{array}$ & English & 3563 & 3594 \\
\hline $\begin{array}{l}\text { HowNet Emotion Words Package of } \\
\text { Chinese }\end{array}$ & Chinese & 3730 & 3116 \\
\hline $\begin{array}{l}\text { Chinese Emotion Vocabulary Ontology } \\
\text { Database }\end{array}$ & Chinese & 11229 & 10784 \\
\hline $\begin{array}{l}\text { Commendatory and Derogatory Words } \\
\text { Thesaurus by Jun Li }\end{array}$ & Chinese & 5564 & 4465 \\
\hline
\end{tabular}

Words with both commendatory and derogatory meanings simultaneously count 93, all of which are excluded from the statistics.

* from Xiaoqian Liu (刘晓倩), 2012

As we can see from the statistics of table 1, Modern Chinese Dictionary (7th edition) and Oxford Advanced Learner's Dictionary (8th edition) marks more derogatory words than commendatory words (the marks of disapproving or “贬义” are almost a hundred times as many as that of approving or “襄义”). This phenomenon is related to the fact that these two dictionaries are comprehensive dictionaries whose main objective is not to define, differentiate, and explain the commendatory and derogatory meanings but to provide sufficient information to help people operate successful communication or do reading and writing smoothly. Since the misuse of derogatory words is more likely to result in misunderstanding in communication and embarrassment or even resentment of both speakers, it is reasonable that comprehensive dictionaries mark more derogatory meanings than commendatory ones. In specialized dictionaries and thesauri, however, the quantity of commendatory and derogatory words in both English and Chinese are roughly 
tantamount. The derogatory words in dictionaries are slightly more than the commendatory ones, but, reversely, the commendatory words in thesauri are slightly more than the derogatory ones.

\subsection{Pot distribution of the commendatory and derogatory expressions in both languages}

POT (parts of speech) is to some extent associated with the inclination of commendatory and derogatory. In both languages, nouns which refer to objects with special features can express positive or negative attitude towards the specific feature. For example, clique and “小团体” (groupuscule) both refer to a small group of people who spend time together frequently and repel outsiders to join them. The derogatory comment is attached to the characteristic of exclusiveness.

Table 2. POT distribution of English and Chinese commendatory and derogatory words and phrases(\%)

COMMENDATOR WORDS

\begin{tabular}{|c|c|c|c|c|}
\hline \multirow{2}{*}{ Dictionaries } & \multicolumn{3}{|c|}{ Words } & \multirow{2}{*}{$\begin{array}{c}\text { Idiomatic } \\
\text { Phrases }\end{array}$} \\
\hline & Adjectives & Nouns & Verbs & \\
\hline $\begin{array}{l}\text { Oxford Advanced Learner's } \\
\text { Dictionary ( } 8^{\text {th }} \text { edition) }\end{array}$ & 65.99 & 20.41 & 0.68 & - \\
\hline $\begin{array}{l}\text { Modern Chinese Dictionary } \\
\left.\text { ( } 7^{\text {th }} \text { edition }\right)\end{array}$ & - & - & - & - \\
\hline $\begin{array}{l}\text { The Usage of Commendatory and } \\
\text { Derogatory Words in Chinese }\end{array}$ & 43.62 & 11.32 & 13.79 & 25.92 \\
\hline
\end{tabular}

DEROGATORY WORDS

\begin{tabular}{|c|c|c|c|c|}
\hline \multirow{2}{*}{ Dictionaries } & \multicolumn{3}{|c|}{ Words } & \multirow{2}{*}{$\begin{array}{r}\text { Idiomatic } \\
\text { Phrases }\end{array}$} \\
\hline & Adjectives & Nouns & Verbs & \\
\hline $\begin{array}{l}\text { Oxford Advanced Learner's } \\
\left.\text { Dictionary ( } 8^{\text {th }} \text { edition }\right)\end{array}$ & 34.89 & 44.44 & 6.47 & - \\
\hline $\begin{array}{l}\text { Modern Chinese Dictionary } \\
\left.\text { ( } 7^{\text {th }} \text { edition }\right)\end{array}$ & 6.32 & 28.42 & 28.95 & 30.53 \\
\hline $\begin{array}{l}\text { The Usage of Commendatory and } \\
\text { Derogatory Words in Chinese }\end{array}$ & 18.78 & 13.29 & 31.86 & 27.01 \\
\hline
\end{tabular}

The types of POT included in the statistics are based on the denotation in dictionaries. Some words are simultaneously denoted by more than one POT and are therefore excluded. Modern Chinese Dictionary (7th edition) only marks two derogatory words, so they are excluded too. Other types of POT, such as adverbs and exclamation, are very few and excluded. The idiomatic phrases with attitudinal marks are very few and excluded. Words with both commendatory and derogatory meanings, which count 13, are excluded.

* from Xiaoqian Liu (刘晓倩), 2012

Table 2 shows the POT distribution of English and Chinese commendatory and derogatory words, including adjective, nouns, verbs, and idiomatic phrases. We can make three conclusions after observation: (1) Among commendatory words, adjectives have the greatest quantity; however, among derogatory words, they do not have the same advantage. (2) Among derogatory words, nouns take occupation of the biggest proportion in English, while verbs are the biggest in Chinese. This pattern is relatively applicable to commendatory words in which, apart from adjectives, English commendatory nouns exceed verbs and Chinese commendatory verbs exceed nouns. (3) Idiomatic phrases take up a great proportion of all the commendatory and derogatory expressions in Chinese; however, the Oxford Advanced Learner's Dictionary (8th edition) marks very few idiomatic phrases with the tag approving and disapproving. The idiomatic phrases included in Chinese dictionaries are mainly four-character idioms which can perform all syntactic components, 
such as the subject, attribute, predicate, etc. In this sense, Chinese idioms are parallel to words, respectively functioning as nouns, adjectives, verbs, etc. as corresponding syntactic components, so they are an important part of commendatory and derogatory vocabulary. That Chinese has more commendatory and derogatory verbs than English is the concrete manifestation of the distinction between subjective and objective narrative style in the two languages.

\section{Sources of the commendatory and derogatory connotation in English and Chinese}

\subsection{Word formation influences commendatory and derogatory meanings}

There are significant differences between English and Chinese word formation, which exert great influence on the commendatory and derogatory meanings in both languages but in different ways. Word formation of Chinese shows the characteristics of analytic language. Disyllable and multisyllable words, taking up most of Chinese vocabulary, are most likely to be compound words, which are formed by combining roots (usually monosyllables) and their basic meanings to form an integrated meaning. Therefore, the commendatory and derogatory meanings of Chinese compound words are borne on each root of the word. The attitudinal connotation of the root (no matter whether it can form a word solely) stems from the basic meaning of it and habitual collocation and context in which the root is frequently applied. Commendatory roots tend to form commendatory words, and derogatory roots tend to form derogatory words.

After analyzing all the dissyllable words in Commendatory and Derogatory Words Thesaurus by Jun $\mathrm{Li}$ (that is 8728 words, $87 \%$ of the thesaurus), we classified the roots into four categories, commendatory roots ( $\mathrm{C}$ roots), derogatory roots ( $\mathrm{D}$ roots), neutral roots ( $\mathrm{N}$ roots), and roots with both commendatory and derogatory meanings (DC roots), according to their own attitudinal tone (commendatory or derogatory), position in the word (1st or 2nd syllable of the disyllable word), and their influence on the attitude of the entire word (commendatory or derogatory). Table 3 shows typical examples of the four types of roots.

$\mathrm{C}$ means commendatory. D means derogatory, $\mathrm{N}$ means neutral. Index refers to comprehensive index of attitude (namely the number of commendatory words minus the number of derogatory words). Appearance refers to the times the root shows up in the thesaurus. For example, “清” (clean) is a commendatory root. It appears in 73 commendatory words in the position of 1st syllable and 3 commendatory words in the position of 2nd syllable. It does not form any derogatory words.

Lexical derivation, roots and suffixes being combined to form new words, is predominant in English word formation. Prefixes are often added to modifying the meaning of the word, and suffixes are often added to change the POT. Compared with Chinese, English roots exert greater influence on the attitudinal inclination of the entire word, whereas affixes seldom carry commendatory or derogatory meanings, which constrain the production of new commendatory and derogatory words.

In most cases, if the root has attitudinal connotation, the derivatives of the root will have the same inclination. For example, pairs of nouns and adjectives such as brave-bravery, honest-honesty, tedium-tedious, and apathy-apathetic have the same commendatory or derogatory meanings with or without affixes. Nevertheless, a small number of English affixes can influence the connotation greater than others. The first example is prefixes and suffixes with derogatory meaning, such as mal- (from French mal, means bad, badly) in maladroit, maltreat, malediction, etc., and -ish (typical or similar to; somewhat) in amateurish, babyish, clannish, outlandish, etc. ( -ish has no derogatory meaning by definition but the fact is that it usually forms adjectives or nouns showing negative attitudes) The second example is prefixes which reverse the meaning of the root, such as im-, in-, and un-. The derivatives and the roots have opposite meanings as well as attitudinal inclination, such as spoiled-unspoiled and consistent-inconsistent. 
Table 3. Typical examples of the four types of roots

\begin{tabular}{|c|c|c|c|c|c|c|c|}
\hline \multirow{2}{*}{ Categories } & \multirow{2}{*}{ roots } & \multicolumn{2}{|c|}{$1^{\text {st }}$ syllable } & \multicolumn{2}{|c|}{$2^{\text {nd }}$ syllable } & \multirow[t]{2}{*}{ Index } & \multirow[t]{2}{*}{ Appearance } \\
\hline & & $\mathrm{C}$ & $\mathrm{D}$ & $\mathrm{C}$ & $\mathrm{D}$ & & \\
\hline \multirow{4}{*}{$\mathrm{C}$ roots } & $\begin{array}{c}\text { 清 } \\
\text { (clean) }\end{array}$ & 73 & 0 & 3 & 0 & 76 & 76 \\
\hline & 名 & & & & & & \\
\hline & $\begin{array}{c}\text { (famous) } \\
\text { 明 }\end{array}$ & 36 & 1 & 25 & 8 & 52 & 70 \\
\hline & (bright) & 40 & 1 & 28 & 0 & 67 & 69 \\
\hline \multirow{3}{*}{ D roots } & $\begin{array}{c}\text { 乱 } \\
\text { (disordered) }\end{array}$ & 0 & 12 & 0 & 37 & -49 & 49 \\
\hline & $\begin{array}{c}\text { 恶 } \\
\text { (wicked) } \\
\text { 败 }\end{array}$ & 0 & 25 & 0 & 14 & -39 & 39 \\
\hline & (failure) & 0 & 23 & 0 & 12 & -35 & 35 \\
\hline \multirow{3}{*}{$\mathrm{N}$ roots } & $\begin{array}{c}\text { 气 } \\
\text { (disposition) }\end{array}$ & 9 & 4 & 38 & 39 & 4 & 90 \\
\hline & $\begin{array}{c}\text { 性 } \\
\text { (property) } \\
\text { 言 }\end{array}$ & 0 & 0 & 11 & 11 & 0 & 22 \\
\hline & (words) & 1 & 0 & 14 & 17 & -2 & 32 \\
\hline \multirow[b]{2}{*}{ DC roots } & $\begin{array}{c}\text { 轻 } \\
\text { (light; frivolous) } \\
\text { 淡 }\end{array}$ & 16 & 14 & 0 & 0 & 2 & 30 \\
\hline & $\begin{array}{l}\text { (calm; banal) } \\
\text { 独 } \\
\text { (independent; } \\
\text { unsocial) }\end{array}$ & 4 & 2 & 3 & 6 & -1 & 15 \\
\hline
\end{tabular}

\subsection{Extension of meaning and the formation of DCN words}

Many of English and Chinese commendatory and derogatory words have more than one meanings with different types of attitudes. Biao Ma (马彪), Li Feng (冯莉) (2010) compared and analyzed the Chinese entries and their English translation in the dictionary, The Usage of Commendatory and Derogatory Words in Chinese. They defined the phenomenon that one word contains more than one meanings with different types of attitudes as “襄贬同词” (DC words) and divided this kind of words into two general categories, typical and atypical. According to their statistics, the proportion of DC words of English is larger than that of Chinese. In their definition, typical DC words are words with commendatory and derogatory meanings, and atypical DC words include words with commendatory and neutral meanings, words with derogatory and neutral meanings, and words with all the three types of attitudes. In order to directly demonstrate the role of neutral meanings in the attitudinal meaning system, we believe that it is necessary to reclassify DC words defined by Biao Ma (马彪) and Li Feng (冯莉) into three types, CN words, DN words, and DC(N) words, and collectively call the them DCN words.

Table 4. The Proportion of Each Type of Commendatory and Derogatory words (\%)

\begin{tabular}{lcccccc}
\hline & $\begin{array}{c}\mathrm{DC}(\mathrm{N}) \\
\text { words }\end{array}$ & $\begin{array}{c}\mathrm{CN} \\
\text { words }\end{array}$ & $\begin{array}{c}\mathrm{DN} \\
\text { words }\end{array}$ & $\begin{array}{c}\mathrm{C} \\
\text { words }\end{array}$ & $\begin{array}{c}\mathrm{D} \\
\text { words }\end{array}$ & $\begin{array}{c}\text { C words \& D } \\
\text { words }\end{array}$ \\
\hline $\begin{array}{c}\text { Oxford Advanced Learner's } \\
\begin{array}{c}\text { Dictionary }\left(8^{\text {th }} \text { edition) }\right. \\
\text { Modern Chinese Dictionary }\end{array}\end{array}$ & 0.78 & 3.78 & 33.00 & 5.92 & 56.52 & 62.44 \\
$\quad 7^{\text {th }}$ edition $)$ & 0 & 0 & 22.92 & 1.04 & 75.52 & 76.56 \\
\hline
\end{tabular}

$\mathrm{DC}(\mathrm{N})$ words refers to words with both commendatory and derogatory meanings, and some of them also have neutral meanings. CN words refer to words with both commendatory and neutral meanings. DN words refers to 
words with both derogatory and neutral meanings. C words and D words respectively refer to words with only one commendatory meaning or derogatory meaning, and C words \& D words adds the number of C words and D words.

Although dictionaries denote more DCN words due to its objective to elucidate confusing words and help people use vocabulary properly, the dictionaries we analyzed are both comprehensive dictionaries of English and Chinese, so they are comparable in the proportion of different types of attitudinal words. From Table 4, we can see that $C$ words and D words of Chinese take up a greater percentage of all the attitudinal words than that of English, namely, DCN words exist more extensively in English than in Chinese.

The larger proportion of $\mathrm{C}$ words and $\mathrm{D}$ words in Chinese is related to word formation and the tradition of integrating subjective stance into narration. In Chinese compound words, the attitudinal meaning of the root can be readily imparted to the entire word, and the attitudinal connotation of the entire word can be easily changed by replacing one of the roots with other roots of opposite connotation. Meanwhile, the tradition of taking and expressing clear stance while writing and speaking (as well as avoiding ambiguity) prompts people to create new words with different connotation, commendatory or derogatory, to precisely convey their opinions and express their attitudes both explicitly and implicitly. However, it usually needs disparate words to express similar concepts in different connotation in English, such as svelte, lean, and thin which all basically mean not covered with much flesh but the former two often with a commendatory attitude and the latter one sometimes with a derogatory attitude. Using DCN words and depending on context to interpret specific commendatory, derogatory, or neutral attitude seems like an approach more in line with the economy principle of language in terms of English. There are no significant differences between English and Chinese in terms of semantic extension approaches, which reflects the similar conception of meaning formation, interaction, and transformation of English and Chinese speakers. The cross-linguistic similarity is also the embodiment of the universality of human cognitive approach.

\section{Use of commendatory and derogatory words in English and Chinese discourse}

\subsection{The usage of commendatory and derogatory words}

Dictionaries and thesauri have statically classified and described the commendatory and derogatory words in Chinese and English, but the actual use of them in speaking or writing discourse is much more complex due to the flexible usage and conversion of attitudinal meanings out of special intention in specific context. In his appraisal system, Martin (2000, 2005) classified different types of attitudes into three categories, judgment, affect, and appreciation. Judgment is the comments on the moral behavior of the commentee based on social esteem and social sanction. Affect is the feelings of the subject. Appreciation is the comments on language/text or objects/phenomena from an aesthetic perspective.

Affect is central to Martin's appraisal system because judgment and appreciation, which are both the comments made by the subject based on socialized standards, can also induce positive or negative emotion. In this sense, judgment and appreciation can be deemed as recontextualized affect. Martin’s appraisal system places emphasis on vocabulary (Zhenhua Wang 王振华, 2001). Common emotional words mostly belong to affect, and commendatory and derogatory words fall into the category of judgment and appreciation. The following discourses are full of commendatory and derogatory words which refer to positive or negative judgment and appreciation. The commentee is also changing throughout the discourses.

In the appraisal system of dialogue and discourse, commendatory and derogatory words are one of the elements to convey tone. They interact and cooperate with other functional words and 
connections to organize different layers of connotation and establish the overall attitude of the dialogue or discourse. For example, without, indicating an adversative relation, affirms the commendatory meaning of modest (not obvious in an unpleasant way), negates the derogatory meaning of slight (trivial, not important), and express more precisely the commendatory attitude towards the moderate writing style of the work. “巨大” (great, prodigious) and “种种” (all kinds of), which modify “声誉” (reputation) and “(奇怪的可怕) 现象” ((grotesque and horrible) phenomenon), respectively intensify the extent of commendatory and derogatory meaning.

\subsection{The conversion of commendatory and derogatory meanings}

The conversion of commendatory and derogatory meanings is abundant in actual use of attitudinal words, and neutral words can also express positive and negative attitudes in specific context. The correspondence between words and meanings are not one-to-one matched or fixed; rather, they vary with the intention of the utterers and the rhetoric techniques used by them. The dynamic changing process of the words and meanings is a reflection of the flexibility and variability of commendatory and derogatory connotation. The research of semantic conversion and its contextual condition of commendatory and derogatory words in dialogue and discourse is conducive to acquire a better understanding of the dynamic function of commendatory and derogatory vocabulary in language communication. The following two paragraphs are comments on a particular person or a type of people, from which we can see an actual practice of commendatory and derogatory words.

There are some examples of conversion of additional attitude. In this case, neutral and commendatory words express derogatory meanings.

(1) Neutral words can have a connotation of commendatory or derogatory attitude based on their basic meaning under the influence of context and the collective meaning of the sentence or paragraph. Exactly, probably, and next president initially describe Duterte's behavior and state, but exactly and probably are not completely neutral and objective because they modified the extent of his achievement and reputation and correspond with the adversative conjunction but to emphasize the derogatory attitude towards his tough-talking campaign strategy. “少数”(a handful of), “不言而 喻”(self-evident), and“不屑一顾”(disdain) are generally neutral words without attitudinal connotation, but in this context, they have a derogatory inclination which is related to their basic meaning. “少数” indicates not as good as the majority, “不言而喻” means lacking justification, and “不屑一顾” criticizes the wrong attitude of the democratic elites.

(2) Commendatory words in ironic tones can convey derogatory meaning and often intensify the negative attitude. Stellar example basically means paragon which is a highly commendatory word; however, when the commenter says Duterte is the "paragon" of bullies and cowards, he uses stellar example sarcastically to clearly express his negative attitude towards Duterte's pretentious courage. “精英”(elites) is originally a commendatory word referring to people who are intelligent, capable, and often outstanding in society or in a specific field (so it is not exactly the same as "elites" in English), but in this context, it makes a contrast with their arrogant attitude and vulgar language and expresses the commenter's derogatory attitude. Although the definition in dictionary remains unchanged, as discrepancy and inequality among different social classes aggravate, “精英” seems to more frequently refer to the self-centred upper class who separate themselves from ordinary people. The change of semantic meaning and connotation reflects the dynamic variation of commendatory and derogatory words in the greater context of society.

The application of commendatory and derogatory words as well as the rhetoric strategy is similar between English and Chinese. Commendatory and derogatory words cannot only convey 
respectively commendatory and derogatory attitude but also reverse their connotation in specific context with combination of other attitudinal words, functional words, and the collective attitudinal tone of the entire discourse. Neutral words can also incline to commendatory or derogatory attitude in specific context. The difference between English and Chinese lies in their respective vocabulary and social morality or aesthetic standards on which the personal attitude is based.

\section{Conclusion}

Focusing on the comparison between English and Chinese commendatory and derogatory words, this study applies methods of statistical analysis and text comparison of dictionaries, thesauri, and a small part of corpora and comes to conclusions ranging from vocabulary scale, distribution of POT (parts of speech), morpheme structure, meaning extension, to use in discourses.

In terms of vocabulary scale, while dictionaries mark more derogatory words than commendatory words, in many thesauri the number of commendatory and derogatory words are roughly tantamount in both languages.

The POT distribution shows different patterns not only between English and Chinese but also between commendatory and derogatory words. For commendatory words, adjectives take up the largest proportion among all POT types in both English and Chinese; for derogatory words, however, in Chinese verbs are proportionately more than nouns, while in English it is nouns that exhibit the advantage. Besides, Chinese idioms play an important role in commendatory and derogatory expression since many dictionaries and thesauri contain a great number of idioms (which is about 30\%) marked as commendatory and derogatory.

English and Chinese are significantly different in word formation and that greatly influence the production of commendatory and derogatory words. Compound is the most common formation approach of Chinese words. The attitudinal connotation of roots can determine that of the entire word. With mostly two roots in a word, the attitudinal meaning can be easily changed by replacing one of the roots to another with an opposite connotation. In English, lexical derivation is the major way to form new words. The meaning and connotation of the word are generally in line with the root, and most affixes exert little impact on the connotation of the entire word.

The DCN phenomenon of commendatory and derogatory words is more common in English than in Chinese, and Chinese has more C words and D words than English. Namely, the commendatory and derogatory meanings of different words are more definite, exclusive, and less ambiguous in Chinese. Although the words and its meanings cannot be matched one-to-one from English to Chinese, both the languages share similar approaches of semantic extension which is the reason for the emergence of DCN words. The four approaches are specialization, extremalization, differentiation of commentee, and metaphorical mapping.

The use of commendatory and derogatory words also shows considerable similarity in English and Chinese discourse. The expression of commendatory and derogatory attitudes can be divided into multiple levels. In each layer, commendatory and derogatory words cooperate with other functional words, connections, and the collective tones to express commendatory and derogatory attitudes. In specific context, commendatory and derogatory words can also reverse their attitudinal connotation to intensify the extent of attitude or to have a rhetoric effect. This conversion of connotation exhibits great variability of commendatory and derogatory words and meanings in practical communication and discourse.

\section{References}

[1] Yan X, Wang J, Chau M. Customer revisit intention to restaurants: Evidence from online reviews[J]. Information Systems Frontiers, 2015, 17(3): 645-657. 
[2] Hong J C, Tai K H, Hwang M Y, et al. Internet cognitive failure affects learning progress as mediated by cognitive anxiety and flow while playing a Chinese antonym synonym game with interacting verbal-analytical and motorcontrol[J]. Computers \& Education, 2016, 100: 32-44.

[3] Хи T, Hua Y. A Study on the CE Translation of Expressions with Chinese Characteristics in 2017 National Government Work Report from the Perspective of Functional Equivalence[J]. Journal of Language Teaching and Research, 2018, 9(2): 379-384.

[4] Wang H. A Corpus-based Contrastive Study of Online News Reports on Economic Crisis-A Critical Discourse Analysis Perspective[J]. Journal of Language Teaching and Research, 2015, 6(3): 627-632.

[5] He X, Zhou X. Contrastive analysis of lexical choice and ideologies in news reporting the same accidents between Chinese and American newspapers [J]. Theory and Practice in Language Studies, 2015, 5(11): 2356-2365.

[6] Shuan-Jun A N, Ling Y, Guang-Hao S. A Brief Review on Semantic Meaning's Developing and Evolution[J]. DEStech Transactions on Social Science, Education and Human Science, 2017 (icesd).

[7] Lan Q, Ma H, Li G. Characters-based sentiment identification method for short and informal Chinese text[J]. Information Discovery and Delivery, 2018, 46(1): 57-66.

[8] Tong Z, Xiao Z, Liu H, et al. A Novel Parallel LSA-SVM Algorithm Based on Semantic Distance for Blog[J]. International Journal of Pattern Recognition and Artificial Intelligence, 2016, 30(09): 1660002.

[9] Dapeng Z. 79. Analysis of Micro-blog Comments Tendentious Vector Based on Machine Learning[J]. Boletín Técnico, ISSN: 0376-723X, 2017, 55(17).

[10] Zuo B. Strategies of Cultural Translation: A Contrastive Analysis of the Two English Versions of Hong Lou Meng[J]. Approaches to Translation Studies, 2015, 42.

[11] ZHANG H. Sexual Discrimination in Italian and Chinese[J]. Studies in Literature and Language, 2016, 12(5): 1619.

[12] Song W U. An Analysis of Reverse Extension of Idiom Semantics[J]. Journal of Leshan Normal University, 2015, 6: 012.

[13] Na D, Xu C. Automatically generation and evaluation of Stop words list for Chinese Patents[J]. TELKOMNIKA (Telecommunication Computing Electronics and Control), 2015, 13(4): 1414-1421.

[14] Zhou G, Wang K, Zhao C, et al. A dynamic trust evaluation mechanism based on affective intensity computing[J]. Security and Communication Networks, 2016, 9(16): 3752-3761.

[15] Monsarrat G. John Ford's Substantive Accidentals in Perkin Warbeck[J]. The Library, 2015, 16(4): $446-457$.

[16] Huang B, Yu G. Research and application of public opinion retrieval based on user behavior modeling[J]. Neurocomputing, 2015, 167: 596-603. 